\title{
Desenvolvimento da Tanatologia: estudos sobre a morte e o morrer
}

\author{
Maria Julia Kovács \\ Universidade de São Paulo, São Paulo-SP, Brasil
}

Resumo: Este artigo discute os principais temas e pesquisas na área da Tanatologia, estudos sobre a morte e o morrer. São apresentados os autores pioneiros que escreveram as primeiras obras de sistematização da Tanatologia entre os quais: Herman Feifel, Robert Kastenbaum e Elizabeth Kübler-Ross, e os principais temas de estudo: luto, violência e guerra, a morte e a TV, cuidados a pacientes gravemente enfermos, além da formação de profissionais da área de saúde e educação para lidar com pessoas vivendo situações de perdas e morte. São feitas propostas de estudos para o futuro desenvolvimento da Tanatologia em nosso país.

Palavras-chave: Educação em relação à morte. Profissionais da saúde. Cuidadores. Formação profissional.

\section{Development of Thanatology: studies about death and dying}

\begin{abstract}
This study discusses the main themes and research related to Thanatology, studies of death and dying. The pioneer experts who wrote the early works that systematize the area are presented: Herman Feifel, Robert Kastenbaum and Elizabeth Kübler-Ross, as well as the main themes of study: bereavement, violence and war, death and TV, palliative care, training of health and education professionals to deal with people experiencing loss and death. Further studies to develop Thanatology in Brazil are proposed.
\end{abstract}

Keywords: Death education. Health professionals. Caregivers. Professional education.

\section{Desarrollo de la Tanatología: estudios sobre la muerte y el morir}

Resumen: Este artículo discutí los temas principales, las investigaciones en el área de la Tanatología y estudios sobre la muerte y el morir. Son presentados los autores pioneros que escribieron las primeras obras sistematizadas de la Tanatología, entre los cuales: Herman Feifel, Robert Kastenbaum y Elizabeth Kübler-Ross. Se presentan también las áreas principales de estudios como: el duelo; la violencia; la guerra; la muerte y la televisión; los cuidados a los pacientes gravemente enfermos y la formación de profesionales del ámbito de la salud y de la educación para trabajar con personas que están viviendo situaciones de pérdida y muerte. También son realizadas propuestas de estudios para el futuro desarrollo de la Tanatología en nuestro país.

Palabras clave: Educación con relación a la muerte. Profesionales de la salud. Cuidadores. Educación profesional. 
Neste artigo nos propomos a apresentar alguns temas da Tanatologia, área de conhecimentos e de aplicação, envolvendo cuidados a pessoas que vivem processos de morte pela perda de pessoas significativas, processos de adoecimento, em decorrência de comportamentos auto-destrutivos, suicídio, ou por causas externas, pela violência presente principalmente nos centros urbanos. Há dois periódicos fundamentais para a sistematização da área: Omega Journal of Death and Dying e Death Studies. Outra fonte importante de consulta na área da Tanatologia é a Association for Death Education (ADEC), fundada em 1970 nos Estados Unidos da América do Norte com os seguintes objetivos: (a) estabelecer redes de interação com profissionais que lidam com o tema; (b) promover encontros, workshops e material escrito para divulgar o assunto; (c) incrementar a educação para a morte e o preparo de profissionais para atuação na área.

No Brasil podemos citar como fontes de referência: o Laboratório de Estudos sobre o Luto na Pontifícia Universidade Católica de São Paulo e o Laboratório de Estudos sobre a Morte no Instituto de Psicologia da Universidade de São Paulo, cujos objetivos são muito semelhantes aos da ADEC. A história brasileira trouxe importantes contribuições para o estudo da Tanatologia. Em 1980 ocorreu o Seminário A Morte e os Mortos na Sociedade Brasileira, coordenado pelo Professor José de Souza Martins, do Departamento de Sociologia da Universidade de São Paulo. As palestras deste Seminário foram publicadas no livro A morte e os mortos na sociedade brasileira (Martins, 1983), abrindo inúmeras perspectivas para a compreensão e investigação sobre o tema.

Wilma Torres foi a primeira psicóloga brasileira que se dedicou à sistematização da área da Tanatologia no Brasil. Criou no Instituto de Pesquisas Psico-Sociais da Fundação Getúlio Vargas, no Rio de Janeiro, um acervo de dados bibliográficos sobre a área, dividido em vários sub-temas, constituindo-se em referência importante àqueles que se iniciam nos estudos sobre a morte (Kovács, 2003). Em 1980 coordenou o I Seminário sobre a Psicologia e a Morte na Fundação Getúlio Vargas no Rio de Janeiro, cujos resultados foram reunidos no livro Psicologia e morte. Neste mesmo ano Wilma Torres propôs o curso Estudos e Pesquisas em Tanatologia com o intuito de promover pesquisas e publicações na área.

Em 1984, foi realizado em Minas Gerais, o I Congresso Internacional de Tanatologia e Prevenção do Suicídio, sob coordenação de Evaldo D’Assumpção, que resultou na publicação da obra Morte, suicídio, uma abordagem multidisciplinar (D'Assumpção, D'Assumpção, \& Bessa, 1984). Na área da enfermagem cabe destacar os trabalhos de Magali Roseira Boemer e Elizabeth Ranier Martins do Valle, docentes da Escola de Enfermagem de Ribeirão Preto da Universidade de São Paulo. Fernandes e Boemer (2005) trazem importante contribuição na questão da educação para a morte no livro O tema da morte em sua dimensão pedagógica.

Em Campinas-SP, Roosevelt Cassorla desenvolveu pesquisa na temática do suicídio. Teve também o mérito de reunir estudos brasileiros sobre o tema da morte e do suicídio nas seguintes obras: $D a$ morte: Estudos brasileiros (Cassorla, 1991a) e Do suicídio: Estudos brasileiros (Cassorla, 1991b). Em 2007, na Faculdade de Medicina da Universidade de São Paulo (FMUSP), foi criado o Curso de Tanatologia e Educação para a Morte, coordenado por Franklin Santana Santos, resultando na obra $A$ arte de morrer: Visões plurais (Incontri \& Santos, 2007). Trata-se de curso pioneiro na FMUSP. Merece citar que, desde 1986, vem sendo oferecida, em nível de graduação, a disciplina Psicologia da morte no Instituto de Psicologia da Universidade de São Paulo, como apresentaremos em outra parte deste texto. Cabe ressaltar que atualmente temos um grande acervo de livros e teses sobre o tema da morte no Brasil e propostas de disciplinas de graduação, pós-graduação e extensão em vários cursos da área da saúde.

\section{Temas em Tanatologia}

A seguir apresentamos as questões relevantes na área que surgiram nestes últimos anos. BluebondLagner (1987), pesquisadora na área do luto infantil, apontou que desde os anos de 1950 há uma sistematização da Tanatologia, mas se questiona sobre a real contribuição que certo tipo de pesquisas oferecem. Muitos estudos tratam de detalhes, isolando alguns 
aspectos do tema da morte, com grande preocupação em definiçõos operacionais. Na década de 1960 houve grandes mudanças na área da Tanatologia, a partir dos trabalhos de Kübler-Ross e Saunders (Kovács, 2003, 2007) que revolucionaram o trabalho com pacientes em estágio terminal da doença e trouxeram o tema da morte para discussão pública, desafiando a mentalidade da morte como tema interdito (Ariès, 1977).

O grande desenvolvimento da Tanatologia ocorreu após as guerras mundiais, com os estudos de Hermann Feifel que escreveu o clássico The meaning of death (Feifel, 1959). Esta obra sinaliza o movimento de conscientização sobre a importância da discussão do tema da morte, apesar da ainda existente mentalidade de interdição do tema. O livro inclui textos sobre filosofia, arte, religião, sociologia. Há artigos de vários autores muito conhecidos, entre os quais destacamos: Jung, A alma e a morte e Marcuse, $A$ ideologia da morte. Nesta obra, encontram-se também artigos temáticos como o capítulo Trajetórias da morte por Glaser e Strauss, e o capítulo Prevenção do suicídio, de Farberow e Schneidman.

Kastenbaum e Aisenberg escreveram o livro Psychology of Death em 1976, traduzido para o português com o título Psicologia da Morte (Kastenbaum \& Aisenberg, 1983), que constitui texto de referência na área. Kastenbaum é responsável pela primeira sistematização da bibliografia sobre o tema e na década de 1970 criou o periódico Omega: Journal of Death and Dying, referência para os estudiosos do tema.

Nos Estados Unidos, Jessica Mitford (1978) escreveu American Way of Death, obra que causou grande polêmica, traçando um retrato da morte no Ocidente, particularmente na América do Norte. Seu texto apresenta o que Ariès (1977) aponta como o retrato da morte tabu, interdito de uma sociedade. Muitas das pesquisas nas décadas de 1970 e de 1980 levaram à consolidação de programas na área da Tanatologia. Segundo Bluebond-Lagner (1987), houve certa estagnação da área pelas exigências e rigor metodológico das pesquisas realizadas na década de 1980, a partir da necessidade de comprovação de tudo o que se dizia. Esta tendência à quantificação pode ter levado à repetição de certos temas, como a avaliação da ansiedade frente à morte, presente em inúmeros artigos. Tal fato pode ter reduzido a profundidade da discussão de uma área tão complexa como a Tanatologia, levando a um afastamento de suas dimensões mais profundas (Kastenbaum \& Sharon, 1995). A hipótese dos autores é que poderia estar operando um mecanismo de defesa nos pesquisadores que não permitiria a entrada em contato com temas envolvendo a subjetividade em relação à morte, o medo da extinção, da aniquilação, entre outras questões. Discutem ainda por qual motivo os profissionais que atuam na área clínica não lêem o que pesquisadores escrevem. Uma primeira resposta pode ser porque as pesquisas repetidas e com excessivo zelo quanto à precisão dos termos, talvez não respondam às questões principais daqueles que cuidam de pessoas vivendo situações de morte.

Passamos a apresentar alguns dos temas atuais de estudo na área da Tanatologia, os quais longe de pretender esgotar a abrangência da área, apresentam um panorama do que vem sendo pesquisado.

\section{Estudos sobre luto}

Parkes (1987), grande autoridade na área do luto, menciona as preocupações atuais nas pesquisas sobre este tema. Nos estudos dos conceitos básicos sobre o luto, há os que verificam como perdas afetam estruturas de significado na vida, já que o luto é considerado uma profunda transição existencial. Outra área importante de estudo é o efeito dos processos do luto no sistema imunológico. Dados epidemiológicos apontam que ocorrem muitas mortes após a viuvez. Vários sintomas psíquicos eram vistos como doença física em pessoas em processo de luto, os médicos eram procurados por pessoas enlutadas que apresentavam sintomas como: depressão, insônia, anorexia, aumento no uso de álcool e drogas. Atualmente muitos destes sintomas são relacionados ao processo de luto e não são mais vistos como patologia, como atestam os estudos de Parkes (1987), Stroebe e Stroebe (1987), entre outros.

Parkes (1987) refere também pesquisas sobre as diferenças nas respostas do luto, envolvendo questões de gênero. Cita autores que estudam a vulnerabilidade e alto risco de mulheres que perdem seus filhos. Menciona estudos sobre diferentes 
manifestações emocionais e a realização de rituais em várias culturas. Parkes, Laungani e Young (1997) publicaram o livro Death and bereavement across the cultures, no qual abordam os principais temas e rituais de várias culturas, entre as quais: a hindu, a budista tibetana, a judaica, a cristã e a islamita. Kastenbaum (1969) se refere a fatores de risco para luto complicado no caso de pessoas idosas, principalmente quando perdem seus filhos adultos. O número de idosos tem aumentado e muitos vivem em situação de risco, com problemas financeiros, isolados, com doenças graves, que podem se agravar com as perdas da vida, constituindo o que o autor denominou sobrecarga de luto. Com o prolongamento do tempo da vida muitos pais estão enterrando seus filhos adultos, e acabam vivendo sozinhos esta perda tão difícil de ser elaborada.

O luto complicado, antigamente denominado de luto patológico suscita controvérsias. Segundo Parkes (1998), é preciso muito cuidado para não se classificar precocemente processos de luto como disfuncionais, quando não seguem estágios ou etapas que durante muito tempo foram considerados como inerentes a seu processo. Para o autor uma cuidadosa avaliação é necessária em todos os casos. A questão do luto complicado é um ponto importante para pesquisas, já que muitos profissionais não estão preparados para lidar com este problema. Segundo Rando (1992/1993), há consequiências sérias quando não se cuida de pessoas que apresentam risco para processos de luto complicado. É fundamental: (a) identificar fatores de risco; (b) delinear tendências sócio-culturais e tecnológicas que possam exacerbá-las; (c) observar o que é necessário ser trabalhado para se evitar um luto complicado.

Para a autora mencionada anteriormente há dificuldades de identificar o que se considera como fatores complicadores. Aponta a necessidade de revisão de alguns conceitos como luto patológico, desajustado, anormal, disfuncional, desviante, entre outros. A tendência é falar em fatores complicadores do luto, pois retira da pessoa a única responsabilidade pelos problemas. Há circunstâncias anteriores à morte, na própria situação e após o óbito que podem dificultar o processo de luto. A autora afirma que alguns processos são importantes para elaboração do luto, entre os quais: (a) reconhecer o luto, (b) reagir à separação, (c) recolher e re-vivenciar as experiências com a pessoa perdida, (d) abandonar ou se desligar de relações antigas, (e) reajustar-se a uma nova situação, (f) reinvestir energia em novas relações.

Entre os fatores que podem causar complicações no processo de luto, observa-se negação e repressão ligadas à perda e à dor. Estes fatores podem ser exacerbados em uma cultura que faz com que as pessoas se controlem, não se manifestem e que vivam como se a morte não existisse. Há também distorções que afetam a expressão do luto, como o adiamento, inibição ou cronificação do processo. Não há padrões que definam quando um ou outro processo está se instalando, porque também devem ser levadas em conta a maneira de ser das pessoas e suas formas de lidar com situações de crise. Estes itens são importantes para serem considerados pelos profissionais que vão cuidar de pessoas enlutadas, não como um padrão a ser imposto sobre elas, mas como sinais a serem observados. Há uma tendência para “adequar" as pessoas, buscando-se normatização, o que não permite que elas possam viver sua tristeza. Podem ocorrer distorções que afetam a expressão do luto, como o adiamento, inibição ou cronificação do processo.

O tipo de morte pode afetar a forma de elaboração do luto. Suicídios e acidentes são as mais graves, pelos aspectos da violência e culpa que provocam. Por outro lado, as mortes de longa duração, com muito sofrimento podem também ser desgastantes. Entre os fatores complicadores deste processo deve ser considerada a relação anterior com o falecido, principalmente a que envolve ambivalência e dependência, problemas mentais e a percepção da falta de apoio social. O luto complicado pode se manifestar por sintomas físicos e mentais. Em muitos casos é difícil separar um processo de luto complicado e a presença de problemas mentais. Esta diferenciação é fundamental ao se pensar nas formas mais adequadas de cuidado.

Mudanças sociais são responsáveis pelas dificuldades de elaboração do luto nos dias atuais. O rápido índice de industrialização, urbanização e o avanço da técnica médica levaram a uma desvalorização dos ritos funerários. A consequiência disto é que ao viverem perdas significativas, as pessoas sentem-se sozinhas, sem saber o que fazer, principalmente quando 
estão distantes de seus familiares, fato comum na atualidade. Nos centros urbanos, houve aumento significativo da violência, dos acidentes e do abuso de drogas, resultando no aumento das mortes violentas e traumáticas, um dos fatores de risco para luto complicado. A morte escancarada por ser inesperada não permite preparo prévio. Envolve múltiplos fatores que podem dificultar a sua elaboração: perdas múltiplas (morte de várias pessoas da mesma família), perdas invertidas (filhos e netos que morrem antes de pais e avós), presença de corpos mutilados, desaparecimento de corpos e cenas de violência (Kóvacs, 2003).

Mortes lentas, em processos crônicos, também causam dor e sofrimento. $\mathrm{O}$ aumento do tempo de vida, também daqueles com doenças lentas e degenerativas, faz com que se viva longos processos de morte, causando desgaste físico e psíquico aos seus cuidadores, que sofrem com a perda da pessoa que conheciam, complicando o processo do luto (Hennezel, 2001). Podem ocorrer sentimentos ambivalentes, tristeza pela perda e raiva pelo abandono, desejo da morte para alívio do sofrimento, que pode provocar culpa, podendo ser este um fator de risco para o luto complicado.

O luto não autorizado também deve ser pesquisado, como apontaram Corr (1998/1999), Doka (1989), Casellato (2005). Um exemplo é a morte por aids, quando companheiros não podem chorar a mútua perda, porque seus amigos e familiares não sabem da relação entre eles. $\mathrm{O}$ aborto é também uma situação de perda não reconhecida, já que a morte ocorre antes da vida ser reconhecida socialmente. Trata-se de grave engano, pois pode haver intenso investimento de amor em uma gravidez com a expectativa do nascimento do filho. Com o aborto inicia-se o processo de luto para elaboração desta perda. Um outro exemplo de luto não autorizado é o dos amantes em situação de adultério, pois sua relação, muitas vezes, não é aceita. Adolescentes, às vezes, não têm seu luto reconhecido, já que freqüentemente se isolam ou se retraem dando idéia de que não estão envolvidos com a situação, o que pode aumentar a sua dor, pois o seu sofrimento não é percebido.

Para o futuro, Parkes (1998) sugere a criação de instituições para prestar cuidados durante o adoecimento e após a morte, o desenvolvimento de programas de cuidados paliativos, os hospices, garantindo-se a especificidade dos trabalhos, que atendam às necessidades de cada população. Por exemplo, em Israel foi criado um serviço de ajuda para viúvas e viúvos da guerra; na África, as instituições cuidam dos órfãos da guerra civil. No Brasil, citamos o trabalho do Laboratório de Estudos sobre a Morte no Instituto de Psicologia da Universidade de São Paulo e do Laboratório de Estudo sobre o Luto, na Pontíficia Universidade Católica de São Paulo. Merece destaque o trabalho de Maria Helena Pereira Franco, coordenadora do Instituto Psicológico de Emergências, que oferece cuidados a sobreviventes e familiares enlutados em catástrofes, como foram os grandes desastres aéreos ocorridos em 2006 e 2007 em nosso país.

\section{Aproximação da morte: cuidado a pacientes no fim da vida}

Uma obra de grande impacto na história da Tanatologia é Sobre a morte e o morrer (KüblerRoss,1987), que fala sobre o cuidado a pacientes gravemente enfermos, destacando a importância da escuta de suas necessidades e seu sofrimento. Ela é mais conhecida pelos estágios (negação, raiva, barganha, depressão e aceitação) vividos por pacientes que recebem o diagnóstico de doença grave. Na verdade, a autora fala das reações de pessoas nesta situação. Ela temia que os profissionais se fixassem na seqüência dos estágios, o que poderia indicar a busca de um padrão ou molde. Entretanto, o fundamental em sua obra é a proposta de comunicação que a autora apresenta. Infelizmente, foi dada mais importância aos estágios propostos do que à sua experiência clínica. (Kovács, 2003, 2007)

Um estudo clássico na pesquisa com pacientes em estágio terminal da doença é o de Hinton (1963), que verificou altos níveis de desespero e depressão em $55 \%$ dos pacientes. Foram observados temas como desligamento das preocupações sociais e a necessidade de cuidado às perdas relacionadas com a doença. Glaser e Strauss (1961) pesquisaram os níveis de consciência de pacientes gravemente enfermos sobre a sua doença e a aproximação da morte, trazendo questões importantes sobre a comunicação com eles. Os autores realizaram estudos em hospitais 
de São Francisco, nos Estados Unidos, com pacientes internados, observando sua relação com a equipe de saúde. Na chamada consciência fechada, o paciente não quer saber de sua doença ou aproximação da morte e o profissional também não fala. Pode também ocorrer fingimento mútuo, não deixar que o outro saiba, o que já se sabe. São apresentadas as trajetórias de mortes rápidas, inesperadas, esperadas ou prolongadas.

O crescente desenvolvimento da medicina e dos hospitais provocou a transferência do lugar da morte para estas instituições. A invenção de procedimentos de alta tecnologia como a hemodiálise trouxe novas questões sobre vida e morte. Uma questão muito difícil para os médicos é decidir quais pacientes serão encaminhados para Unidades de Terapia Intensiva (UTI) com possibilidade de serem salvos, e quais não irão, com risco de morte.

A questão dos transplantes trouxe também reviravoltas em relação ao momento da morte, dividindo-a em duas vertentes: morte clínica e cerebral. Cria-se aí um dilema ético envolvendo o atestado da morte para retirada de órgãos, com o coração ainda batendo, o que afeta profundamente o imaginário popular que entende que há vida enquanto o coração bate, mesmo que o cérebro esteja morto. Com o desenvolvimento da tecnologia médica os hospitais tornaram-se "instituições para a cura". Novas questões sobre vida e morte se apresentam então. O ser humano tem direito à vida e também à morte digna, surgindo a questão: qual é o real papel das Unidades de Terapia Intensiva? Salvar vidas ou prolongar mortes? Vemos na prática médica esta mesma contradição: por um lado, tenta-se prolongar a vida a todo custo e, por outro, há uma busca para mortes com dignidade. Questões sobre o fim da vida mostram a importância do entrelaçamento da Tanatologia com a bioética, uma discussão interdisciplinar.

Uma das áreas que demanda maior profundidade envolve os cuidados a pacientes no fim da vida, observando suas necessidades, a estrutura de atendimento nos hospitais e outros recursos como hospices, unidades de cuidados paliativos e o cuidado domiciliar. Inclui temas polêmicos como morrer com dignidade, eutanásia, e o suicídio assistido.
Schultz e Schlarb (1987) apontam a magnitude do problema, já que é crescente o número de idosos doentes e pacientes em estágio avançado da doença. As pesquisas na área de cuidados paliativos envolvem temas como: agravamento da doença e sintomas múltiplos e incapacitantes, transmissão de más notícias, enfrentamento da proximidade da morte, processo do luto antecipatório e o luto dos familiares (Kovács, 2003).

Em 1995, foi realizado o estudo Study to understand prognosis and preferences for outcomes and risk of treatment (SUPPORT), citado por Lynn (1997), com o objetivo principal de colher informações sobre pacientes em estágio de terminalidade e seus familiares. Esta pesquisa durou quatro anos, envolveu 9000 pacientes de cinco hospitais de ensino nos Estados Unidos, procurando verificar a causa do sofrimento na situação da morte. Os pesquisadores verificaram que $55 \%$ dos pacientes estavam conscientes nos três dias que antecederam a sua morte, $40 \%$ apresentavam dores insuportáveis e $80 \%$ tinham fadiga extrema, $63 \%$ relataram ter dificuldade para tolerar o grande sofrimento físico e emocional relacionado ao agravamento da doença e com o estágio final da vida. O estudo indicou também que $20 \%$ das pessoas morrem nas UTIs. Daqueles que lá estiveram e saíram: $76 \%$ relataram desconforto, $72 \%$ falaram que tiveram muita sede, $68 \%$ sentiram sono, $63 \%$ ansiedade, $56 \%$ dor e $52 \%$ raiva. Observa-se, então, um grande índice de sofrimento, que se torna ainda mais grave para aqueles casos nos quais a doença chegou a um ponto de irreversibilidade. Nestes casos, medidas invasivas podem se tornar inúteis. A referida pesquisa trouxe elementos importantes para a discussão e implantação dos programas de cuidados paliativos.

Os estudos sobre crianças e adultos com doenças em estágio avançado numa abordagem qualitativa trazem dados importantes sobre os momentos vividos no diagnóstico, no transcorrer da doença e tratamento, e no estágio final, envolvendo os sentimentos relacionados com cada fase e as formas de enfrentamento utilizadas.

As primeiras pesquisas nesta área fizeram comparações entre os cuidados oferecidos em hospitais convencionais e os programas de cuidados paliativos. 
Os programas de cuidados paliativos oferecem: alternativas de tratamento menos agressivo, melhor controle de sintomas, família mais próxima dos pacientes, embora com nível maior de estresse e preocupação, custos menores; menores índices de depressão. Atualmente estas diferenças entre modalidades de atendimento não são tão marcantes e as pesquisas passaram a envolver temas como morte com dignidade e as necessidades dos pacientes no fim da vida (Pessini, 2004).

Há dificuldades de pesquisas com pacientes gravemente enfermos. Estudos quantitativos podem trazer dados para o desenvolvimento da área, mas podem se tornar inviáveis se demandarem grande número de pacientes com características semelhantes. Por outro lado, pesquisas qualitativas, depoimentos, histórias de vida podem trazer de forma mais aprofundada o universo e a percepção de pessoas que estão vivendo tão próximas do fim da vida. As escalas de qualidade de vida podem não trazer toda a dimensão deste momento da existência. $\mathrm{O}$ melhor é sempre perguntar, ao próprio paciente, se suas necessidades foram atendidas e ficar atento a como ele fala de sua própria dor e sofrimento (Kovács, 1998).

Outra área importante de desenvolvimento é a de cuidados paliativos a pacientes idosos. É um grande desafio cuidar de seus sintomas incapacitantes, sendo os mais graves: demenciação, esclerose e confusão mental, como apontam Py e Burlá (2004).

Em duas pesquisas realizadas com pacientes portadores de câncer avançado na Unidade de Tratamento da Dor e Cuidados Paliativos no Hospital Amaral Carvalho em Jaú-SP, foi discutido como avaliar sua qualidade de vida na busca por melhor compreensão de suas necessidades. Questões atuais ligadas ao cuidado com pacientes com doença avançada envolvem a discussão sobre a morte com dignidade e o direito de escolha da própria morte (Kovács, 1998, Kovács, Kobayashi, Santos, \& Avancini, 2001).

Uma outra área importante de trabalho e de pesquisa nos estudos sobre a morte é a formação e preparação de profissionais de saúde para lidar com pacientes com doença grave e seus familiares. Benoliel (1987), enfermeira e pesquisadora, aponta questões importantes para reflexão sobre o tema. Várias pesquisas mostraram como profissionais lidam com a morte, seus índices de ansiedade, medo e de que modo enfrentam a situação. Entre as principais dificuldades relatadas estão: como falar com pacientes sobre o agravamento da doença e a possibilidade da morte, como realizar os procedimentos usuais em pacientes sem prognóstico de cura e a sensação de impotência que estas situações provocam. A autora apresenta ainda a importância dos cursos sobre a morte e o morrer para estes profissionais, trazendo a possibilidade do auto-conhecimento e a capacitação para lidar com pacientes próximos à morte. Verificou que alguns cursos para a formação de profissionais de saúde incluem o tema da morte em uma aula ou módulo. Propõe que sejam criados cursos específicos de Tanatologia, com duração que favoreça, além dos conhecimentos técnicos, a possibilidade de entrar em contato com valores e sentimentos mais profundos.

Na mesma direção da proposta da autora mencionada, desde 1986 tem sido oferecida uma disciplina optativa com o título Psicologia da Morte no Instituto de Psicologia da Universidade de São Paulo, com os seguintes objetivos: (a) sensibilizar o aluno para os sentimentos e reflexões sobre os vários pontos abordados no curso, como por exemplo: suicídio, aproximação da morte, perda de pessoas da mesma faixa etária por acidentes, entre outras; (b) apresentar várias abordagens teóricas sobre a questão da morte; (c) propor reflexões sobre a prática vivida, aprendizagem que envolve aspectos cognitivos e afetivos propiciando buscar o sentido individual e o coletivo. Trata-se da possibilidade de uma constante revisão da atuação do estagiário e do profissional, levando à construção de seu conhecimento.

O curso aborda vários temas que poderão ser incluídos ou aprofundados dependendo do interesse dos alunos. Citamos a seguir aqueles que compõem a base da disciplina Psicologia da Morte (Kovács, 2003): (a) Retratos da morte no Ocidente: domada, interdita, rehumanizada e escancarada. A visão oriental da morte; (b) Morte no processo do desenvolvimento humano. O desenvolvimento do conceito de morte em crianças e adolescentes. A questão da morte na fase adulta e no envelhecimento. Elaboração psíquica da morte nas várias fases do desenvolvimento; (c) Abordagens teóricas do tema da morte; (d) As perdas na existência e o processo do luto. Cuidados psicológicos a pessoas 
enlutadas. Fatores de risco para luto complicado; (e) Comportamentos auto-destrutivos e o suicídio. Programas de prevenção do suicídio. Cuidados psicológicos a pessoas em risco e seus familiares; (f) Pacientes gravemente enfermos. Cuidados no fim da vida. Programas de cuidados paliativos; (g) Bioética nas questões da vida e da morte. Eutanásia, distanásia, suicídio assistido; (h) A questão da morte nas instituições de saúde e educação. $\mathrm{O}$ trabalho do psicólogo com pessoas vivendo situações de perda e morte.

\section{Tanatologia: violência e guerras}

Outra área importante de estudos da Tanatologia é o estudo da violência, presente nas guerras e na guerrilha urbana. Fulton e Owen (1987-1988) realizaram um estudo sobre a compreensão da morte no século XX. Comparam as concepções de morte daqueles que nasceram antes da Segunda Guerra Mundial e os que nasceram depois. Os primeiros têm hoje mais de 70 anos. Quando nasceram a expectativa de vida não chegava aos 50 anos e muitos morriam de doença infecciosa em casa. Quem nasceu depois da Segunda Guerra Mundial já tinha uma expectativa de vida de mais de 67 anos e muitos não têm contato próximo com a morte. As doenças são combatidas com tecnologia avançada e as mortes tornam-se distantes ou invisíveis, ocorrendo, em grande parte, fora do lar, nos hospitais.

Os autores mencionados anteriormente fizeram um estudo sobre as mudanças da mentalidade sobre a morte no século XX, a partir das guerras atuais. Nas obras de Ariès (1977), observa-se como durante muito tempo as guerras envolviam combates entre pessoas, sendo que os soldados morriam como heróis ou anônimos, mas tinham tempo para elaborar a morte e realizar os rituais de absolvição e despedida. A guerra do século XX é diferente, o soldado é desconhecido e anônimo. Não morrem apenas os soldados, mas também civis, mulheres e crianças. Muitos não compreendem as razões das guerras.

Umberson e Henderson (1992) realizaram uma pesquisa interessante sobre a guerra do Golfo, como exemplo de guerra do século XX. O que observaram foi ambivalência e a negação da morte, como se fosse possível fazer uma guerra sem mortes. A linguagem, as metáforas e os eufemismos usados nas notícias e reportagens sobre esta guerra provocam algumas reflexões. Observa-se negação, distanciamento, mecanismos de desumanização e desensibilização. Não há menção direta da morte, como se ela ocorresse por acidente ou acaso. A ênfase é dada à descrição da destruição de locais e equipamentos. Não se usa a palavra morte e sim destruição ou eliminação. Os prejuízos são justificados como sendo o preço da guerra.

A negação parece assegurar que, ao não se falar de morte, era como se esta não existisse, confirmando a idéia de que dessa forma não se matavam civis inocentes, a não ser por acidente. Morriam os "culpados", aqueles a serviço do inimigo. A alta teconologia evita mortes, pois são atacados alvos inimigos, não se "mata" pessoas. O público vai sendo preparado para as mortes "necessárias" da guerra. Procura-se desumanizar os "inimigos", afirmando que as mortes são necessárias visando um objetivo maior. As mortes são causadas pela intransigência dos líderes e não pelos morteiros.

Observa-se, então, um grande paradoxo: a guerra é promovida, mas se imagina que é possível a troca de morteiros e foguetes, sem que mortes ocorram, por isso são ocultadas quando acontecem. Os morteiros e sua capacidade de destruição são espetaculares, são disparados à noite para não serem vistos pelos envolvidos, mas proporcionam um show para quem assiste pela TV.

\section{Morte na TV}

A TV tem também influência na maneira de se encarar a morte. Segundo Umberson e Henderson (1992), as estatísticas são alarmantes: as pessoas que nasceram na metade do século $\mathrm{XX}$, a primeira geração da televisão, já viram 10.000 homicídios, estupros e outras formas de violência e agressões nesta mídia.

Com o intuito de oferecer diversão, a TV apresenta programas extremamente violentos, mesmo que embalados numa linguagem destinada a crianças. Tome-se como exemplo o desenho Tom \& Jerry, no qual os dois personagens ficam se perseguindo, se machucando e se destruindo para na cena seguinte aparecerem lépidos, exagerando a idéia infantil de que a morte é reversível e que atos de violência não têm 
efeitos duradouros (Kovács, 1992). Por outro lado, ao trazer cenas de guerra ou violência urbana, como homicídios ou acidentes, os veículos de comunicação podem passar a informação de que a violência é natural.

A TV mostra também as mortes de personagens importantes. Nos Estados Unidos foi o assassinato de Kennedy e, no Brasil, a morte de Tancredo Neves e de Ayrton Senna. Nestes casos, a morte é vista pela tela opaca da TV, mas envolve a coletividade em um processo de luto, o que ficou muito presente na morte de Diana, princesa de Gales. Os noticiários da TV mostram também imagens de morte de pessoas anônimas, figuras esquálidas, retratos da pobreza, fome e morte. Neste caso não há individualidade ou privacidade. A câmera foca o rosto das vítimas ou dos familiares para captar as imagens de sofrimento. Uma imagem freqüente, nos anos 1980, foi a dos doentes com aids para divulgar o perigo da doença, a idéia da morte. Foram expostos rostos e corpos com a justificativa do esclarecimento, mas sem medir as conseqüências desta exposição.

Muitas notícias trazidas pela TV têm características comuns, apresentando cenas e imagens fortes, de dor, perda e sofrimento que provocam sentimentos intensos, sem permitir tempo para reflexão e elaboração, sendo seguidas por comerciais ou por assuntos mais amenos. Esta é uma forma de banalizar a morte, com a idéia de chocar, mas não comprometer as pessoas, pois a vida deve continuar. Esta é também a mensagem trazida por certos filmes que mostram o detalhamento da violência em quadros demorados e repetidos, eclipsando o significado da morte. Diferentemente da duração dos noticiários da $\mathrm{TV}$, os filmes não têm a justificativa da falta de tempo (Kovács, 2003).

A morte no século $\mathrm{XX}$ ocorre freqüentemente nos hospitais, principalmente se decorrentes de doenças do coração, câncer, derrames e outras. A TV exibe, principalmente, a violência e os jovens morrendo. É bem verdade que este último tipo de morte vem aumentando de maneira significativa. O que é específico da morte na TV é o seu caráter de impessoalidade. Não podemos deixar de mencionar que há certa fascinação frente à morte, uma necessidade de consumo, que pode ser observado pelo aumento de audiência quando o tema se faz presente.
Fulton e Owen (1987/1988) apontam que pode haver um abalo na idéia de imortalidade, quando se vê tantas mortes e tão próximas, provocando sensação de desespero. Para evitar o sentimento de extinção existencial criam-se personagens que trazem uma idéia de imortalidade, como por exemplo, James Bond, que sempre desafia a morte enfrentando a destruição, o Super-Homem do século XX/XXI. Reproduz bem a contradição: a busca da imortalidade e a presença constante da morte na vida e nos meios de comunicação. Como se vê, este é um tema importante de estudo da Tanatologia nos dias atuais.

\section{Educação para a morte}

A Association for Death Education and Counselling (ADEC), já citada neste artigo, convidou Stillion, especialista na área de suicídio, para fazer, em 1989, uma retrospectiva dos estudos sobre o tema da morte desde a sua fundação, em 1976. A autora retoma a perspectiva da morte interdita e negada e o desenvolvimento de uma medicina fundamentalmente ligada à cura em hospitais com alta tecnologia. Nos Estados Unidos, o cuidado dos corpos pode ser realizado por estranhos nas funeral homes, que têm como objetivo maquiar o corpo para tornar a morte menos visível.

A TV passa a ser um dos grandes educadores sobre morte para crianças com cenas de violência repetidas à exaustão, dificultando a compreensão da irreversibilidade da morte, ao trazer, recorrentemente, a imagem do acidente ou da pessoa viva. Em 2008, acompanhamos repetidamente, a tragédia da menina Isabella Oliveira Nardoni cuja história de horror trouxe às crianças a imagem de pais ou madrastas que podem atirá-las pela janela.

AADEC promoveu vários encontros, conferências, mesas redondas, material escrito, workshops, vídeos sobre temas relacionados à Tanatologia. Foram escritas diretrizes para profissionais, estudantes e especialistas foram certificados. A força tarefa da ADEC elaborou um catálogo com as principais obras referentes ao tema e os currículos dos cursos de Tanatologia, além de realizar o levantamento sobre educação para a morte em pré-escolas, em instituições de ensino fundamental e médio e em universidades. 
Stillion (1989) aponta para a importância de se formar educadores habilitados para criar e oferecer cursos de Tanatologia com os mais variados temas. O periódico Death Studies é a voz desta Associação e em conjunto com o periódico Omega: Journal of Death and Dying, procuram traçar as linhas mestras das reflexões, pesquisas e práticas profissionais sobre o tema da morte e da preparação de profissionais competentes.

Kenneth Doka (1990), um dos tanatologistas mais conhecidos e editor do periódico Omega: Journal of Death and Dying apresenta uma relação de obras clássicas na área da Tanatologia. Em sua opinião, livros podem ajudar pessoas a lidarem com seus sentimentos diante das perdas da vida, propondo o recurso da biblioterapia. Menciona a obra clássica Sobre a morte e o morrer de Elizabeth Kübler-Ross (1987). O livro oferece a um público não especializado, o esclarecimento sobre questões envolvendo o tema da morte. $\mathrm{O}$ autor cita obras que tratam do processo de luto de pessoas conhecidas, que relatam sua experiência de perda. Como a sociedade não permite, em muitas situações, que as pessoas expressem seu pesar ou falem sobre o assunto, elas podem sofrer intensamente. Muitas pessoas não sabem se o que estão sentindo faz parte do processo do luto, imaginando que estejam loucas e que talvez nunca consigam sair de sua dor. Neste caso, os livros podem ajudar porque, a partir dos relatos apresentados, poderão observar semelhanças com seus processos vividos, as dificuldades encontradas, além de sugestão de estratégias de enfrentamento. A biblioterapia pode ser importante auxiliar no processo de cuidados de pessoas vivendo situações de perda e morte. Entretanto, a recomendação de livros para este fim deve ser feita com muito cuidado. Alguns livros podem ter fortes repercussões para uma pessoa e serem irrelevantes ou até danosos para outra, provocando ainda mais ansiedade.

Vislumbrando o futuro vemos temas que precisam de desenvolvimento (Kovács, 2003). Um deles é a abordagem da morte nas escolas e preparação de educadores para essa atividade. Esse tema nos parece fundamental, uma vez que estão aumentando significativamente as mortes de crianças e adolescentes, por diversas causas, principalmente pela violência, abuso de drogas e outras situações de risco. É importante, também, abrir espaços de comunicação sobre a morte para o público leigo e para estudantes e profissionais interessados. Para isso, o Laboratório de Estudos sobre a Morte do Instituto de Psicologia da Universidade de São Paulo vem criando recursos áudio-visuais para facilitação da discussão sobre o tema. Entre os projetos já desenvolvidos mencionamos "Falando de morte", com quatro filmes: crianças, adolescente, idosos e profissionais de saúde.

Entendemos como educação para a morte a que se faz no cotidiano, envolvendo comunicação, relacionamentos, perdas, situações limites, nas quais reviravoltas podem ocorrer em qualquer fase do desenvolvimento. Está calcada nos questionamentos, na procura do autoconhecimento, na busca de sentido para a vida, o verdadeiro sentido de aprendizagem significativa. Nunca se trata de dar receitas, respostas simples, padrões, normas ou doutrinação, é a busca do sentido para toda a existência.

\section{Referências}

Ariès, P. (1977). História da morte no Ocidente (S. V. Siqueira, Trad.). Rio de Janeiro: Francisco Alves. (Original publicado em 1975)

Benoliel, J. Q. (1987). Health care providers and dying patients: Critical issues in terminal care. Omega: Journal of Death and Dying, 18, 341-363.

Bluebond-Lagner, M. (1987). Wither thou goest. Introduction. Omega: Journal of Death and Dying, 18, 257-263.

Casellato, G. (Org.). (2005). Dor silenciosa ou dor silenciada? Perdas e lutos não reconhecidos por enlutados e sociedade. Campinas, SP: Livro Pleno.

Cassorla, R. M. S. (1991a). (Org.). Da morte: Estudos brasileiros. Campinas, SP: Papirus.

Cassorla, R. M. S. (1991b) (Org.). Do suicídio: Estudos brasileiros. Campinas, SP: Papirus.

Corr, C. A. (1998/1999). Enhancing the concept of disenfranchised grief. Omega: Journal of Death and Dying, 38, 1-20. 
D’Assumpção, E., D’Assumpção, G., \& Bessa, H. A. (1984). Morte e suicídio: Uma abordagem multidisciplinar. Petrópolis, RJ: Vozes.

Doka, K. (1989). Disenfranchised grief: Recognizing hidden sorrow. New York: Lexington Books.

Doka, K. J. (1990). The therapeutic bookshelf. Omega: Journal of Death and Dying, 21, 321-326.

Feifel, H. (1959). The meaning of death. New York: Mc Graw Hill.

Fernandes, M. L. B., \& Boemer, M. R. (2005). $O$ tema da morte na sua dimensão pedagógica. Londrina, PR: EdUEL.

Fulton, R., \& Owen, G. (1987/1988). Death and society in the twentieth century in America. Omega: Journal of Death and Dying, 18, 379-395.

Glaser, B. G., \& Strauss, A. (1961). Awareness of dying. Chicago, IL: Aldine.

Hennezel, M. (2001). Nós não nos despedimos. Lisboa: Editorial Notícias.

Hinton, J. M. (1963). The physical and mental distress of the dying. Quarterly Journal of Medicine, $32,1-21$.

Incontri, D., \& Santos, F. S. (2007). (Orgs.). A arte de morrer: Visões plurais. São Paulo: Comenius.

Kastenbaum, R. (1969). Death and bereavement in later life. In A. H. Kutcher (Ed.), Death and bereavement (pp. 28-54). New York: Springfield.

Kastenbaum, R., \& Aisenberg, R. (1983). Psicologia da morte. São Paulo: Pioneira.

Kastenbaum, R., \& Sharon, T. (1995). Cookies baking, coffee brewing toward a contextual theory of dying. Omega: Journal of Death and Dying, 31, 175-187.

Kovács, M. J. (1992). Morte e desenvolvimento humano. São Paulo: Casa do Psicólogo.

Kovács, M. J. (1998). Avaliação da qualidade de vida em pacientes oncológicos em estado avançado da doença. In M. M. J. Carvalho (Org.), Psicooncologia no Brasil: Resgatando o viver (pp. 159-185). São Paulo: Summus.
Kovács, M. J. (2003). Educação para a morte: Desafio na formação de profissionais de saúde e educação. São Paulo: Casa do Psicólogo.

Kovács, M. J. (2007). Contribuições de Elizabeth Kübler-Ross nos estudos sobre a morte e o morrer. In D. Incontri \& F. S. Santos (Orgs.), A arte de morrer: Visões plurais (pp. 207-216). São Paulo: Comenius.

Kovács, M. J., Kobayashi, C., Santos, A. B. B., \& Avancini, D. C. F. (2001). Implantação de um serviço de plantão psicológico em uma unidade de cuidados paliativos. Boletim de Psicologia, 51, 1-22.

Kübler-Ross, E. (1987). Sobre a morte e o morrer (T. L. Kipnis, Trad.) São Paulo: Martins Fontes. (Original publicado em 1969)

Lynn, J. (1997). Study to understand prognosis and preferences for outcomes and risk of treatment (Support). Annals of Intern Medicine, 126, 97106.

Martins, J. S. (Org.). (1983). A morte e os mortos na sociedade brasileira. São Paulo: Hucitec.

Mitford, J. (1978). The american way of death. London: Virago.

Parkes, C. M. (1987). Research: Bereavement. Omega: Journal of Death and Dying, 18, 365377.

Parkes, C. M., Laungani, P., \& Young, B. (Eds.). (1997). Death and bereavement across the cultures. London: Routledge.

Parkes, C. M. (1998). Luto: Estudos sobre a perda na vida adulta (M. H. P. Franco, Trad). São Paulo: Summus. (Original publicado em 1972)

Pessini, L. (2004). A filosofia de cuidados paliativos: Uma resposta diante da obstinação terapêutica. In L. Pessini \& L. Bertanchini (Orgs.), Humanização e cuidados paliativos (pp. 181208). São Paulo: Loyola.

Py, L., \& Burlá, C. (2004). Humanizando o final da vida e pacientes idosos, manejo clínico e terminalidade. In L. Pessini \& L. Bertanchini (Orgs.), Humanização e cuidados paliativos (pp. 135-148). São Paulo: Loyola. 
Rando, T. (1992/1993). The increasing prevalence of complicated mourning: The onslaught is just beginning. Omega: Journal of Death and Dying, 26, 43-59.

Schultz, R., \& Schlarb, J. (1987). Two decades of research on dying: What do we know about the patient? Omega: Journal of Death and Dying, 18, 299-317.

Stillion, J. (1989). Association for death education and counselling: An organization for our times and for our future. Death Studies, 13, 191-201.

Stroebe, W., \& Stroebe, M. S. (1987). Bereavement and health: The psychological and physical consequences of partner loss. Cambridge: Cambridge University.

Umberson, D., \& Henderson, K. (1992). The social construction of death in the Gulf War. Omega: Journal of Death and Dying, 25, 1-15.

Artigo recebido em 05/05/2008.

Aceito para publicação em 07/10/2008.

Endereço para correspondência:

Profa. Dra. Maria Julia Kovács. Universidade de São Paulo. Instituto de Psicologia. Departamento de Psicologia da Aprendizagem, do Desenvolvimento e da Personalidade. Av. Mello Moraes, 1721. CEP 05508-900. São Paulo-SP, Brasil. E-mail: mjkorag@usp.br

Maria Julia Kovács é Professora Associada do Instituto de Psicologia da Universidade de São Paulo, campus São Paulo. 